\title{
Micro porosity of coated paper affected by modified pigment particles
}

\begin{abstract}
Expensive synthetic coating materials can be replaced with natural coatings and surface treatment with natural components and additives which are friendlier to the environment and have normally better special surface properties. However, special properties can be obtained with surface functionalization by chemical or surface geometry modification. Beside optical properties, the trends of lightweight materials, i.e. reducing grammage by using nano materials and products (i.e. NMP $\mathrm{N}$-Methyl-2-Pyrrolidone), lower specific energy requirement and costs, forces increasing of pigments usage. Results of survey showed that surface properties of papers coated with modified ground calcium carbonate (GCC), required for inkjet printing with water-based inks had improved significantly, whereas the increment of printed object has minimum differentiation from the ideal, computer-based character.
\end{abstract}

\section{KEY WORDS}

GCC, modified pigments, coated paper, inkjet printing, bleeding, wicking

\section{Klemen Možina Gregor Franken}

University of Ljubljana, Faculty of Natural Science and Engineering, Ljubljana, Slovenia

Corresponding author: Klemen Možina

e-mail:

klemen.mozina@ntf.uni-lj.si

First recieved: 18.09.2018.

Accepted: 24.10.2018.

\section{Introduction}

The paper industry has realized high-speed inkjet printing as a vast new business opportunity. Now days, the inkjet printing has become the dominant printing method for commercial large format and desktop small format printing of photos, graphic art and documents, as well as being a valuable proofing device. Inkjet printing provides unique advantages of high colour gamut, high image quality and print on demand at affordable prices (Lee, Joyce \& Fleming, 2004; Lee, Joyce \& Fleming 2005; Lee et al., 2005; Chen \& Burch, 2007).

Unlike solvent-based liquid or paste ink systems used in conventional printing, i.e. offset, screen, gravure, etc., the ink systems used for inkjet printing are water based, containing 65 to $95 \%$ of water. In order to absorb large quantities of ink quickly and produce high-quality colour images with inkjet printers, specialty media are required (Chapman \& Michos, 2000).
To achieve a smoother and a more printable surface, paper and paperboard grades are often coated. The coating layer is applied to the substrate as a wet coating by several techniques. The coating consists of pigment, binder, thickener and water. The solids content of a coating varies between 50 and $70 \%$, which depends upon the properties of the substrate, the required rheological properties of a coating dispersion, the coating technique, the coating speed, etc. On industrial scale, it is desirable for coating to keep the solids content as high as possible, partly for environmental reasons, partly to save energy during the drying stage, which has a large impact on the process economics. Under laboratory conditions, however, where the coating speed is considerably lower and unconventional substrates are sometimes used, a paper coating of low solids content is often easier to handle. The substrate can be coated in a single layer or in several layers. A common coating technique is to apply a pre-coating, i.e. to cover the fibre surface and to provide a smooth base for the subsequent application of one or two top-coating layers to improve the optical properties and printability. 
A dry coating layer has a typical coating weight of 5-20 $\mathrm{g} / \mathrm{m}^{2}$ with a thickness of 5-20 $\mu \mathrm{m}$ (Bohlin, 2013).

Over the past few years, there have been a variety of different coating formulations and technologies developed to meet the needs of inkjet printing. Former studies indicated that the optical properties and printability of microporous inkjet coated paper is strongly controlled by the pigment types used in the coating formulations. Small particle size of coting pigment, i.e. GCC (Ground Calcium Carbonate) and large surface area, provide special pore structures and surfaces to rapidly absorb the aqueous ink vehicle away from the surface and into the porous microstructure (Khoultchaev \& Graczyk, 2001; Batz-Sohn, Storeck \& Scharfe, 2004; Monie \& Krupkin, 2006). To be able to provide mentioned acceptations and demands when using inkjet printing, the R\&D activities in paper mills are going into a new, i.e. modified coating pigments, mostly on the bases of GCC development with special properties as the answer on the increasing market demands (Kettle, Lamminmäki, \& Gane, 2010; Rutar, Rutar \& Možina, 2011; Smithers/PIRA, 2018).

Inkjet printing is non-contact printing technique. The only contact is in the moment of ink transfer on the paper surface. For good reproduction and print quality, the coated papers are used, where the coated layer serves as micro-porous substrate. Dye in ink penetrates into the micro-porous substrate along the capillaries and the depth of the penetration is the criteria for the printout quality (Svanholm, 2007; Patrick, 2010). An inkjet printing test for the vaterite-coated papers resulted in high print quality, without bleeding or wicking problems because of the good wettability tendency (similar with silica). In the paper coating substrate, the fixing agent, i.e. poly-DADMAC (Polydiallyldimethylammonium Chloride) was added (Mori, 2010). For liquids, e.g. ink or printing colour, their penetration into the paper is more important than flow through the paper structure. Liquid penetration takes place by capillary flow in capillaries between particles in coated layer structure. The penetration flow is expressed by the Young-Laplace equation (Equation 1) and Lukas-Washburn equations (Equation 2) (Niskanen, 1998; Holik, 2006). Liquid transfer on/in paper surface is represented with Young-Laplace equation:

$$
\Delta \mathrm{p}=2 \gamma_{\lambda} \cos (\theta) \frac{1}{\mathrm{r}}
$$

while wettability or liquid penetration is expressed by Lukas-Washburn-equation:

$$
\mathrm{h}^{2}=\frac{\mathrm{r}^{2} \mathrm{t}}{4 \eta}\left(\frac{2 \gamma \cos \theta}{\mathrm{r}}+\Delta \mathrm{p}\right)
$$

where is: $\Delta p$ - external pressure difference, $\gamma_{\lambda}$ - surface tension, $\theta$ - contact angle between the liquid and the capillary wall, $r$ - pore radius, $\eta$ - fluid viscosity, $\mathrm{p}$ - liquid pressure in the nip and $\mathrm{h}$ - distance travelled, $\mathrm{t}$ - time.

Solely surface tension and gravity effects drive the flow of the liquid. In printing and converting processes the nip pressure forces liquid to penetrate into the paper. Regarding printing process, we can talk about liquid transfer and wettability of the printing substrate. On the other hand, in printing and converting processes the nip pressure forces liquid to penetrate into the paper. Further, surface tension is small compared to external pressure. Lucas-Washburn equation (e.g. Equation 2) can be rewritten in Equation 3, (it is previously stated what the $p$ stands for).

$\mathrm{h}^{2}=\frac{2 \mathrm{r}^{2} \mathrm{tp}}{\mathrm{k \eta}}$

The Kozeny constant, $k$, is included to account for irregular and tortuous pores. Kozeny-Carman equation (e.g. Equation 4) gives a quantitative relation between permeability and porosity. The model assumes a uniform bed of packed particles that have an effective particle diameter $\left(\mathrm{d}_{\mathrm{eff}}\right)$.

$$
\mathrm{K}_{v}=\frac{\phi^{3} \mathrm{~d}_{\mathrm{eff}}^{2}}{36(1-\phi)^{2} \mathrm{k}}
$$

where is: $\phi$ - porosity, $\mathrm{d}_{\text {eff }}$ - effective diameter (influence on pore volume and shape), and k- Kozeny constant.

Equations 3 and 4 express the phenomena of liquid transfer in to the printing substrate. The Lukas-Washburn equation predicts the depth of liquid penetration. In converting process (e.g. calendaring, paper surface, mostly coated surface) the external pressure compresses paper structure, which reduces pore volume and consequently reduces liquid penetration.

\section{Materials and Methods}

On a laboratory scale trials of preparing modified GCC pigment and afterwards coating of paper surface was performed. Average specific surface is of the GCC was measured according to the Brunauer-Emmett-Teller (BET) technique (International Organisation for Standardization, 2010), on the apparatus Micrometrics New TriStar II Surface Area and Porosity System (Table 1). The main purpose of all trials was to find out the procedure of pigment modification to encounter the market demands for the inkjet printing papers and paperboards.

Therefore, one base paper (regular office white paper, produced from primary cellulose fibers, i.e. Navigator Universal) with $80 \mathrm{~g} / \mathrm{m}^{2}$, have been only coated on an upper (A) side of a paper, i.e. on a RK Multicoated K303, with addition of coating substrate between 8 to $10 \mathrm{~g} / \mathrm{m}^{2}$. 
Afterword the colour printouts were done on a HP Office-jet 6000 printer (thermal $4800 \times 1200$ dpi, dyebased inks, $\min 1.3 \mathrm{pl}$.).

Table 1

Modified pigment preparation

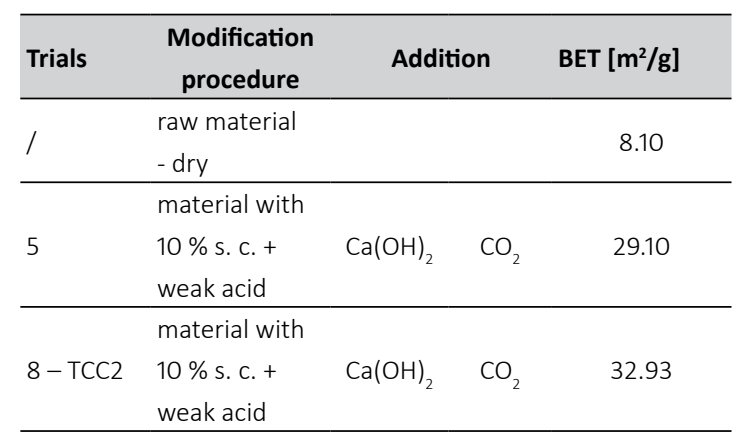

Segment of printouts, i.e. number 8 and letter $E$, selected upon their geometric figure, where in case of number 8 , the lines cross at the middle and leave small inside circle, i.e. in ideal case unprinted "white dot" and in case of letter $\mathrm{E}$, the middle horizontal line, which is usually shorter and less intensely expressed than the line above and below, has a significant impact on a clarity and quality of printouts, which were at the end evaluated with ImageJ, where the bleeding and wicking were calculated. Images, i.e. 8 and $E$, were captured under a microscope, Nikon SMZ800, at magnification $8 \times$. In the end, the captured pictures were processed in Adobe Photoshop, where the image size was determined and exported into the ImageJ. Coloured picture was transformed in ImageJ into the bit format, upon which the ratio between the black and white area was calculated.

\section{Results and discussion}

Cationic treatment, i.e. with quaternary ammonium salt, of GCC pigment particles, with the $\mathrm{pH} 10.2$ and zeta potential between -30 and $-40 \mathrm{mV}$ (moderate stability), has a positive influence on capturing the anionic dye and therefore keeps it from uncontrolled spreading on the paper surface, i.e. bleeding and wicking. The GCC, with special technological preparation procedure, where the electrical charge as well as the shape and size of the pigment particles, were modified according to the values in Table 1. The specific surface area was enlarged and the same time, the particles electric charge had increased from 17 to $12 \mathrm{mV}$ at $\mathrm{pH} 7.85$. With the addition of weak and/or strong acids the specific surface area changed from 8 to $33 \mathrm{~m}^{2} / \mathrm{g}$ (Table 1). The trials of coating base wood free paper with three coatings, with standard wet grinded GCC pigment quality, modified pigment TCC2 and reference pigment, were also done (Table 2). The main differences between used materials, like specific surface area and mean particle diameter presented in Table 2 show the quantitative effect the modification of GCC has.
Modification of D50, i.e. $50 \%$ of particles are size $2 \mu \mathrm{m}$, has an $80.9 \%$ increasement in specific surface area.

\section{Table 2}

Pigments characteristics

\begin{tabular}{lcc}
\hline Pigment sample & D50 [\%] & BET [ $\left.\mathbf{m}^{2} / \mathbf{g}\right]$ \\
\hline standard quality & $0.686 \mu \mathrm{m}$ & 12.24 \\
\hline TCC 2 & $1.241 \mu \mathrm{m}$ & 32.93 \\
\hline reference & $1.353 \mu \mathrm{m}$ & 60.74 \\
\hline
\end{tabular}

Distribution and particle form are well presented on the SEM pictures (Figure 1-3), where the extend of micro porosity of calendared coated paper is recognised. Coating layer consistent from modified TCC2 (Figure 2) is more condense due to the increment of specific area. Further, the GCC particles are more equally distributed with smaller tendency towards forming large agglomeration structures which usually results in printing irregularities. To be able to confirm the extend of GCC modification has on printing quality, the inkjet print was performed on studied coated papers.

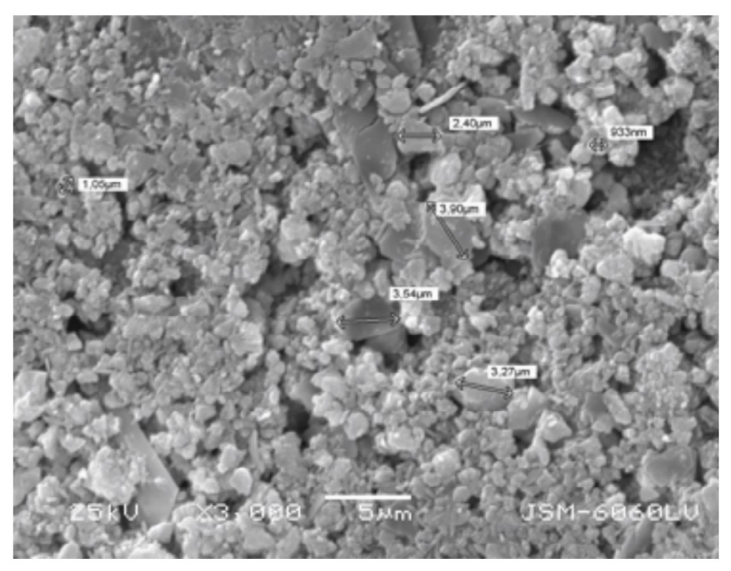

» Figure 1: Standard product

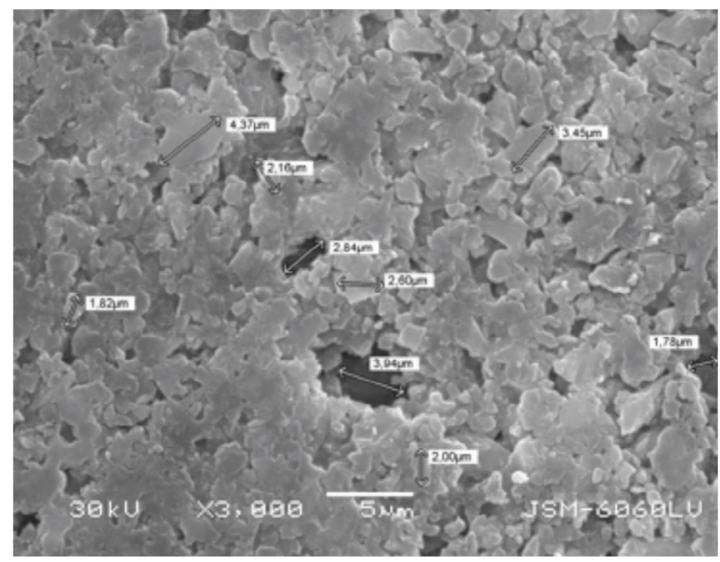

» Figure 2: Modified product TCC2 


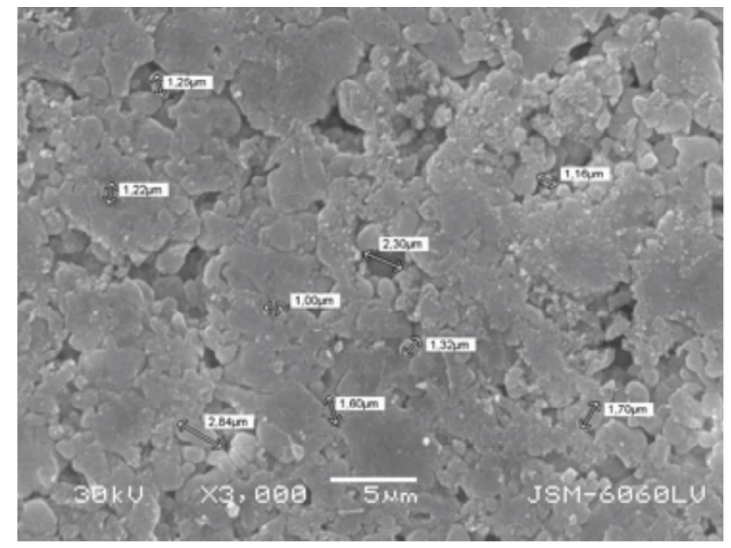

» Figure 3: Reference product

In the Table 3, 4 are presented results of bleeding and in Table 5 the results of wicking. Values were calculated upon the image analysis in ImageJ. The effect of the pigment particles modification on micro-porosity and capability to capturing anionic dye in inkjet printing technique, showed significant contribution to the print quality. Bleeding of yellow eight on printed black background (Figure 4) has less, $0.07 \%$, increment than the black eight printed on yellow background (Figure 5), $10.89 \%$.

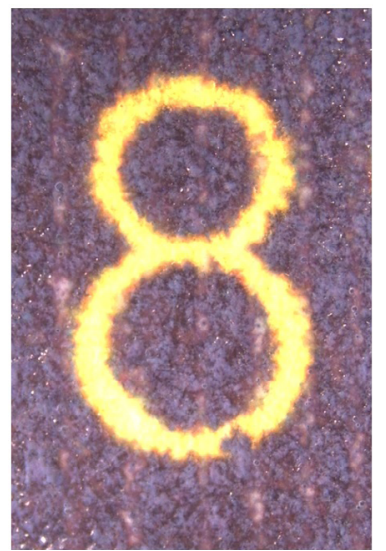

» Figure 4: Yellow eight on printed black background

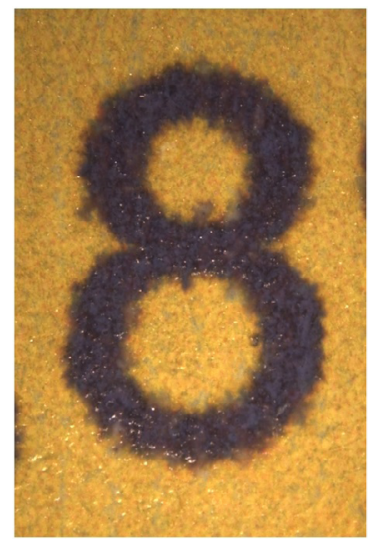

» Figure 5: Black eight on printed yellow background.
On the other hand, when considering wicking, modification of pigment particles has a small effect on increment of perimeter, i.e. $0.63 \mathrm{~mm}$, to the ideal shape of letter $E$, which is computer generated letter. Modification of pigment particles in such a way, can have perceptible effect on printout quality, therefore it should be considered as a valuable tool to increase the micro porosity and decrease the bleeding and wicking, namely water-soluble inks, i.e. used in inkjet printers.

\section{Table 3}

Bleeding of black 8 on yellow

\begin{tabular}{lcccc}
\hline Specimen & $\begin{array}{c}\text { Picture of } \\
\text { bleeding }\end{array}$ & Area [\%] & Increment [\%] & Share [\%] \\
\hline standard & $\mathbf{8}$ & 38.95 & -5.72 & -12.81 \\
\hline TCC2 & $\mathbf{8}$ & 55.56 & 10.89 & 24.38 \\
\hline Ref. & $\mathbf{8}$ & 44.68 & 0.01 & 0.02 \\
\hline Ideal & $\mathbf{8}$ & 44.67 & & \\
\hline
\end{tabular}

Table 4

Bleeding of yellow 8 on black

\begin{tabular}{lcccc}
\hline Specimen & $\begin{array}{r}\text { Picture of } \\
\text { bleeding }\end{array}$ & Area [\%] & Increment [\%] & Share [\%] \\
\hline standard & $\mathbf{8}$ & 38.16 & 1.86 & 5.12 \\
\hline TCC2 & $\mathbf{8}$ & 36.37 & 0.07 & 0.19 \\
\hline Ref. & $\mathbf{8}$ & 36.29 & -0.01 & -0.03 \\
\hline Ideal & $\mathbf{8}$ & 36.30 & & \\
\hline
\end{tabular}

Table 5

Wicking

\begin{tabular}{lllllll}
\hline Specimen & $\begin{array}{c}\text { Picture of } \\
\text { bleeding }\end{array}$ & $\begin{array}{c}\text { Area } \\
{\left[\mathrm{mm}^{2}\right]}\end{array}$ & $\begin{array}{c}\text { Perimeter } \\
{[\mathrm{mm}]}\end{array}$ & $\begin{array}{c}\text { Increment } \\
\text { of Perimeter } \\
{[\mathrm{mm}]}\end{array}$ & $\begin{array}{c}\text { Share } \\
{[\%]}\end{array}$ \\
\hline standard & & 21.82 & 60.50 & -2.80 & -4.42 \\
\hline TCC2 & & 24.68 & 63.93 & 0.63 & 1.00 \\
\hline Ref. & & 24.13 & 63.86 & 0.56 & 0.88 \\
\hline Ideal & & 23.30 & 63.30 & & \\
\hline
\end{tabular}

\section{Conclusions}

Ground calcium carbonate (GCC) is the mayor component in the paper coating dispersing solution in $\mathrm{EU}$ 
paper mills, which is mainly due to the environment and economics. Paper coating formulation and its performance also present important surface interactions. Coating structure and its effects on printability can also be interpreted considering thermodynamic properties between mineral and adhesive particles. Paper printability can be investigated and improved according to a surface chemistry approach. The concept of surface engineering demonstrated in the article can also result in a product, i.e. paper with higher added value. Therefore, successful pigment engineering, like finer particle size distribution, effective dispersing system and other procedures that are reflected in modified specific area, electric charge, etc., provide a high value of significant properties of the coated paper surfaces used as a dominant graphic material in versatile printing technics, in our case, inkjet. The increment of studied objects, i.e. 8 and $E$, differed little from the ideal shaped character. Concepts of surface chemistry are practically involved in all stages of paper manufacturing, but always with the thought on an end user, i.e. printing houses.

\section{References}

Batz-Sohn, C., Storeck, A. \& Scharfe, S. (2004) Tailor-Made Silica and Alumina for Inkjet Media Coatings. In: NIP \& Digital Fabrication Conference. 20th International Conference on Digital Printing Technologies Final Program and Proceeding, Society for Imaging Science and Technology, pp. 805-810.

Bohlin, E. (2013) Surface and porous structure of pigment coatings. PhD thesis. Karlstad University Studies, Sweden.

Chapman, D. M. \& Michos, D. (2000) Novel Silica Gels for Glossy, Ink-Receptive Coatings. Journal of Imaging Science and Technology. 44 (5), 418-422.

Chen, T. \& Burch, E. (2007) High Performance Porous Inkjet Media Derived from Fumed Silica. In: NIP \& Digital Fabrication Conference. Society for Imaging Science and Technology, Alaska, USA. pp. 110-113.

Kettle, J., Lamminmäki, T. \& Gane, P. (2010) A review of modified surfaces for high speed inkjet coating. Surface and Coating Technology. 204 (12-13), 2103-2109. Available from: doi: 10.1016/j.surfcoat.2009.10.035 Holik, H. (2006) Handbook of Paper and Board. Weinheim, Wiley-VCH.
International Organisation for Standardization. (2010) ISO 9277:2010. Determination of the specific surface area of solids by gas adsorption - BET method. Geneva, International Organisation for Standardization.

Khoultchaev, K. \& Graczyk, T. (2001) Influence of Polymer-Polymer Interactions on properties of Inkjet Coatings. Journal of Imaging Science and Technology. 45 (1), 16-23.

Lee, H. K., Joyce, M. K. \& Fleming, P. D. (2004) Influence of Pigment Particle on Gloss and Printability for Inkjet Paper Coatings. In: NIP \& Digital Fabrication Conference. Society for Imaging Science and Technology, Salt Lake City, USA. pp. 934-939.

Lee, H. K., Joyce, M. K. \& Fleming, P. D. (2005) Influence of Pigment Particle Size and Pigment Ratio on Printability of Glossy Inkjet Paper Coatings. Journal of Imaging Science and Technology. 49 (1), 54-60.

Lee, H. K., Joyce, M. K., Fleming, P. D. \& Cawthorne, J. E. (2005) Influence of Silica and Alumina Oxide on Coating Structure and Print Quality of Inkjet Papers. TAPPI Journal. 4 (2), 11-16.

Monie, S. A. \& Krupkin, N. V. (2006) Effect of Silica Pore Characteristics on Inkjet Print Attributes. In: NIP \& Digital Fabrication Conference. Society for Imaging Science and Technology, Denver, USA. pp. 611-614.

Mori, Y., Enomae, T. \& Isogai, A. (2010) Application of vaterite-type calcium carbonate prepared by ultrasound for ink jet paper. Journal of Imaging Science and Technology. 54 (2), 20504-1-20504-6. Available form: doi: 10.2352/J.ImagingSci.Technol.2010.54.2.020504

Niskanen, K. (1998) Paper Physics. Papermaking Science and Technology, Book 16. Technical Association of the Pulp \& Paper Industry, USA.

Patrick, K. A (2010) A tailored approach to kaolin products. TAPPI/PIMA, Paper 360. November/December, 40-42.

Rutar, V., Rutar, R. \& Možina K. (2011) Coating pigments, calendering and effect on gloss, printing gloss and coated papers suitability for ink-jet printing. 17 International symposium in the field of pulp, paper, packaging and graphics, Zlatibor, Srbija. pp. 137-142.

Svanholm, E. (2007) Printability and Ink-Coating Interactions in Inkjet Printing. PhD thesis. Karlstad University.

Smithers/PIRA. (2018) The Future of Speciality Papers to 2022. Available from: https://www.smitherspira. com/industry-market-reports/paper/specialty-papers-to-2022 [Accessed: 15th October 2018].

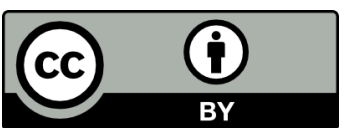

(C) 2018 Authors. Published by the University of Novi Sad, Faculty of Technical Sciences, Department of Graphic Engineering and Design. This article is an open access article distributed under the terms and conditions of the Creative Commons Attribution license 3.0 Serbia (http://creativecommons.org/licenses/by/3.0/rs/). 